\title{
Case studies of technology roadmapping in mining
}

\author{
Joe Amadi-Echendu*, Obbie Lephauphau, Macks Maswanganyi, \\ Malusi Mkhize
}

Graduate School of Technology Management, University of Pretoria, Pretoria, South Africa

\section{A R T I C L E I N F O}

\section{JEL Classification:}

L23, 031

Keywords:

Technology planning and forecasting Mining

Technology roadmapping

\begin{abstract}
A B S T R A C T
Mining is a long established art with legacy processes and institutional structures that face rapidly changing technological environments. The perception is that technology planning and forecasting receives priority attention only as far as they may be linked to making production tonnage in the short term, thus giving the impression that new technology may be introduced without developing a culture and operational requirements that influence successful implementation of new technologies. With depleting ore grades of existing mines, and the prevailing global financial crisis making it prohibitive to develop richer sources, mining is considered to be short-term risk averse and this accentuates a more conservative approach towards technology planning and forecasting. Based on surveys and interviews with practicing miners, this paper discusses three case studies on the practice of technology planning and forecasting in mining firms. It is evident that technology planning and forecasting, and particularly the use of the roadmapping approach, is not a 'culture' common to mining firms.
\end{abstract}

(c) 2010 Elsevier B.V. All rights reserved.

\section{Introduction}

The magnitude and speed of technological change are increasing as well as the scale, dynamics and complexity of the global market place. Sustainable management of an asset over its entire life cycle is vital to firms searching for ways to improve business performance. Changing technology affects the decision making process for sustainable asset management whether the asset is a resource like coal or

\footnotetext{
* Corresponding author at: Graduate School of Technology Management, Engineering Building 2, Room 4-19.1 Main Campus, University of Pretoria, Pretoria 0002, South Africa. Tel.: +27 12420 5793; fax: +27 123625307.

E-mail address: joe.amadi-echendu@up.ac.za (J. Amadi-Echendu).
} 
platinum, or even an engineered equipment such as a continuous miner. It is important for an assetintensive organization to apply a structured approach with effective processes and systems to acquire, adopt and align technological innovations with its strategic objectives so as to achieve improved business performance in both the short- and long-terms.

Mining has played, and continues to play a pivotal role in the growth and development of nations. For instance, coal mining provides a basic raw material for energy supply. Global demand of coal is projected to rise by $1.4 \%$ a year, with this demand expected to be strongest in the developing world where the requirement for electricity power generation is expected to account for the bulk of this increase in demand (Dyk, 2008).

Mines tend to be relatively large operations in numerous underground sections as well as in big open pits depending on the resource and its geology. Mining methods such as drill and blast, continuous, and longwall, are carried out using engineered assets that involve large earthmoving equipment such as bucket-wheels, continuous miners, conveyor systems, draglines, feeder-breakers, excavators, roof bolters, shovels, shuttle cars, and trucks. The reliability and availability of the production equipment, the workforce, and the support systems have a large impact on mine performance. Preventative, predictive and proactive maintenance are essential strategies that should increase production uptime, and when correctly implemented, they could result in substantial savings, since the maintenance cost in the mining industry can be as high as half of the production cost (Campbell and Reyes-Picknell, 2006).

Extrapolating from a Mandate Framework Document for the South African Coal Roadmap (1998), depleting ore grades and new legislation have wide ramifications and provide impetus for the adoption of new business drivers, hence, mining firms need to channel their capabilities towards new strategic directions. Although production tonnage has been a key driver, however, health, safety and energy efficiency issues have taken on more significance, resulting in many new legislative requirements that also impact on cost and competitiveness. Safety is a major issue in mining and does attract stringent statutory regulations. Varying, often hazardous, confined work space, and poor manmachine interface impact on productivity and cost. Environmental protection through 'green technologies' is also at premium cost to miners (Limpitlaw, 2004). The challenge is to improve ergonomic conditions by reducing exposure to hazards and minimizing recordable accident case rates towards zero. To achieve such targets requires training and the deployment of advanced technologies in production equipment and business systems, including automation, satellite communications, smart sensors, and robotics (Willis et al., 2004). Remote, real-time monitoring, diagnostics and prognostics are becoming essential technological features of modern-day coal mining operations (Peterson et al., 2001).

With mining operations increasingly dependent on the application of various technologies, so also has technology management become an essential business activity for miners. Mining is a long established art with legacy processes and institutional structures that are not immune to technology changes but, there is a perception that miners tend to approach technology planning and forecasting in an adhoc manner (Garcia and Bray, 1997). Changes in technology may be abrupt and discontinuous, thus presenting significant uncertainties in mining environments characterized by traditional inertia and conventionally high resistance to change. For some miners, the implication is that they may have to rapidly abandon conventional techniques in favour of adopting potentially disruptive technologies, irrespective of whether the technological resources are in the form of physical artefacts (such as hardware or firmware), or in the form of technological processes, i.e., business procedures that encompass 'new ways of doing things'. An unstructured approach to the introduction of technology without adequate consideration of the rigours of the mining environment could be premature to mining culture (Hung et al., 2001; Warhurst and Bridge, 1996; Lee and Kang, 2008).

Firms recognize that technology can be a driver for growth and development, and many managers are aware that technology can be deployed to sustain strategic business objectives. Identifying, selecting and implementing the most suitable technologies from different alternatives invoke serious decision-making around value creation and competitive advantage. From the point of view of delivering value, many managers are, at least, aware of the strategic importance of technology because of increasing costs, complexity, and rate of change of technology, and these issues are compounded by competition for, and the globalization of, the sources of technology. The management of technology 
for business benefit requires effective processes and systems to be put in place to ensure that capabilities are aligned to strategic objectives.

As high grade ore depletes with prohibitive costs for developing richer sources, mining firms need to continuously harness effective equipment and processing technologies to sustain productive capacity, and when necessitated by market conditions, to deliver more products. For example, it is important that specifying the requirements for technology improvement in equipment should not be done in an adhoc manner, especially where the asset-intensive operator depends on original equipment manufacturers and vendors for the actual implementation of the required technologies. It has been suggested (Galvin, 2004; Phaal et al., 2005; Albright and Kappel, 2003) that the application of "technology roadmapping" can provide a structured approach towards planning and coordination at a strategic level for better technology investment decisions.

While assuming that technology planning and forecasting is important to mining (Amadi-Echendu et al., 2008), this paper briefly describes three case studies of how mining firms tackle the issues of technology planning and forecasting especially in the context of depleting ore grades and new legislation. Of particular interest is whether mining firms utilize a structured approach, and, if so, what approaches, methods and tools are preferred? In "Technology planning, forecasting and roadmapping" section of the paper, we provide a very brief review of some attendant literature on technology planning and forecasting in mining. "Case studies" section contains an overview of our research and results, and the findings are summarized in "Discussion" section.

\section{Technology planning, forecasting and roadmapping}

Technology management is multidisciplinary and multifunctional, and the processes include inter alia identification, acquisition, selection, and exploration; planning, directing, controlling, protecting, developing and implementing technological capabilities to maintain market position and business performance in accordance with the company's strategic and operational objectives (cf. Phaal et al., 2005; McCathy, 2003).

Technology planning and forecasting are strategic issues and technology roadmapping is emerging as an approach that can be used to ensure that the technological resources within an organization are aligned towards firm's strategic objectives (Probert et al., 2003). The roadmapping approach provides a "structured (and often graphical) means for exploring and communicating the relationships between evolving and developing markets, products and technologies over time" (Phaal et al., 2004:5). Garcia and Bray (1997) describe technology roadmapping as a "... needs-driven planning process to help identify, select, and develop technology alternatives to satisfy a set of product/services..."

The future presents high levels of uncertainties, discontinuities and complexities (Vojak and Chambers, 2004) spurred by rapid and unprecedented changes in socio-political, economic and technological situations. These changes create increasingly dynamic and borderless environments that may be very different in the future (Saritas and Oner (2004:29)), therefore roadmapping and other strategic planning tools require cautious application so as to avoid or minimize the chances of introducing chaos. Kappel (2001:47) cautions that although roadmaps may provide a logical view of the long term, however, many uncertainties associated with long term planning may make roadmaps unstable if not reviewed regularly. Combining long and short term views increase the validity of roadmaps thus mitigating the risks of uncertainties, discontinuities and complexities in the long term (Kostoff et al., 2004).

Information about strategic objectives, coupled with analysis of capabilities and technology alternatives is far more important than following a precise process and format. It may not be surprising that the terms 'scenario planning' and 'trend analysis' may be better understood by some of the practitioners. For mining firms, the emphasis should be on identifying, selecting, acquiring, exploiting and protecting those technologies that should be deployed to satisfy production, health, safety and energy imperatives if they are to operate sustainable businesses. In this regard, Phaal et al. (2004) have identified (i) initiative overload, (ii) distraction from short term tasks, and (iii) inadequate information and knowledge, as some of the factors that may hinder successful application of the technology roadmapping approach. 
Establishing technology management processes in mining is an ongoing challenge that requires effective communication, dialogue and understanding between the commercial and technological functions of a firm (Willis et al., 2004). Although planning and forecasting should be needs-driven to identify, acquire, and implement sustainable technologies however, Kappel (2001) reiterates that appropriate tools and processes will be required to formally link strategy, operations and technological innovations. In essence, a structured approach to technology management should help a mining firm to address at least two questions:

i. Which distinctive technological competences and capabilities are necessary to establish and maintain health, safety and environmental compliance, as well as production targets?

ii. Which technologies should be implemented and how should these technologies be embodied in business systems and engineered production assets?

\section{Case studies}

Case study 1-coal mining technology management drivers and techniques

In our first case study, we approached 100 people involved in coal mining, including 80 from coal mines, 4 from research and service providers, and 16 from government establishments. The convenience sample was drawn from 60 participants attending a Coaltech 2020 colloquium, and 40 members of the South African Colliery Engineers Association (SACEA). Twenty respondents completed the questionnaire while only five respondents agreed to participate in a telephonic interview. Seventeen respondents held positions ranging from senior engineer to general manager. As shown in Fig. 1, the respondents ranked safety, health and environmental regulations as top drivers for technological innovations in coal mining, citing, for example, that the introduction of remotely controlled continuous miner removes the human operator from the very dangerous coal face.

It is remarkable that factors such as process innovation, technology obsolescence and competition ranked relatively lower in this regard. A respondent even commented that there is tendency for vendors to supply technologies that address regulatory concerns, "because the mines can acquire those technologies just to comply with the regulations".

Interestingly, as depicted in Fig. 2, most of the respondents' organizations used 'scenario planning and trend extrapolation' more often for technology planning and forecasting, rather than the roadmapping technique as propounded in literature. Only three respondents were unaware of the

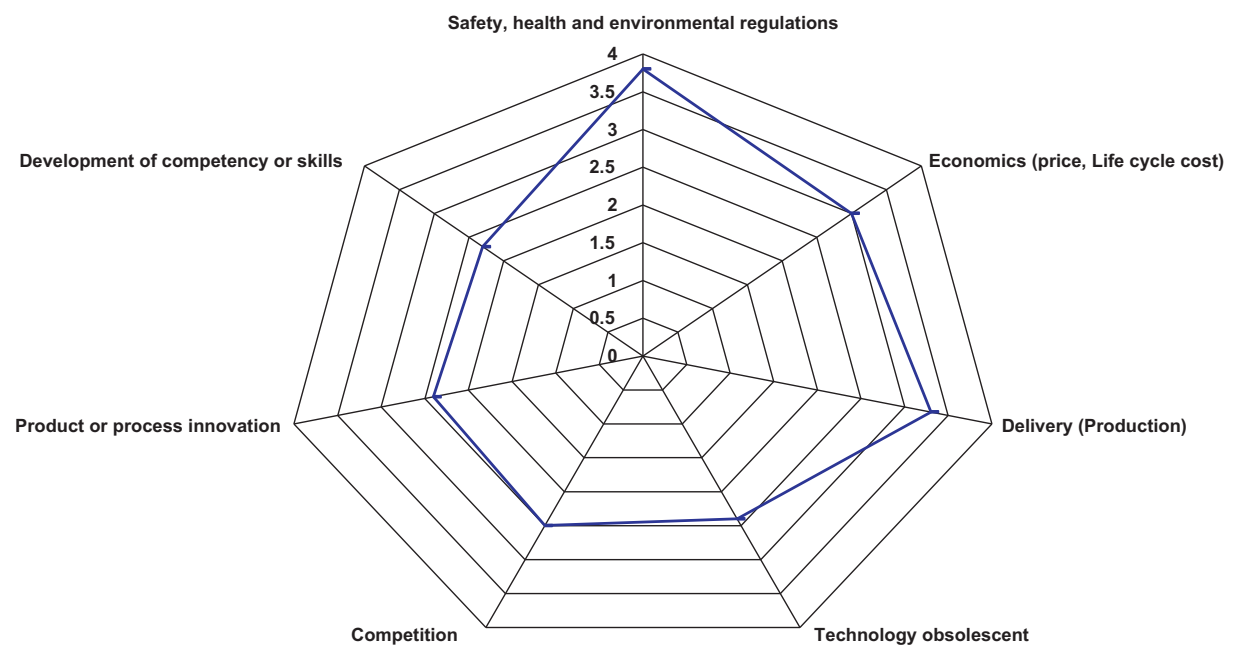

Fig. 1. Drivers for technological innovation in coal mining. 


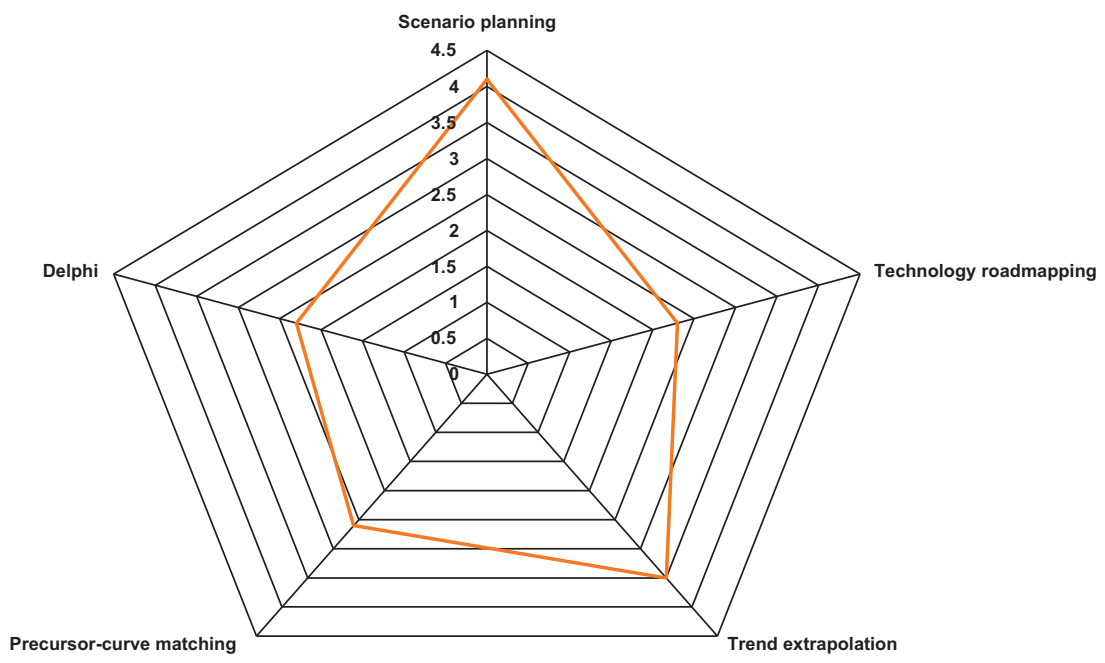

Fig. 2. Techniques for technology planning and forecasting.

roadmapping technique. This feedback is not surprising from an asset operator's viewpoint because the asset is a means to an end but not the end itself.

\section{Case study 2-coal mining technology requirements specification}

With the indication from Case Study 1 that safety is the dominant driver for technological innovations, while scenario planning is the preferred approach to technology planning and forecasting in coal mining, our second case study then examined how the requirements for technological innovations are specified in a typical coal mining firm.

Burgelman et al. (2004), Adner and Levinthal (2001), and Gindy et al. (2006) discuss extensively the issues involved in specifying user requirements for technological innovations from an operational viewpoint. It is paramount to a coal miner that technology is acquired and implemented, first, to resolve operational problems, and second, to provide competitive advantage. Irrespective of whether or not the circumstance is technology-push or market-pull, creators of technological innovations maybe unacquainted with the impact on operational environments, therefore, the onus is upon the operator to establish a credible process (Von Hippel, 1994) for specifying requirements for technology upgrades in operational equipment. Whereas mining personnel can identify needs for operational improvements, it is not uncommon to find that the process for converting needs into technical requirements tends to be adhoc (Edmondson et al., 2003; Garg and Garg, 2005; Jain et al., 2003).

Although the coal mining firm in our case study depends on the original equipment manufacturer for technology upgrades on its continuous miners, however, the firm has developed internal capacity for the manufacture of shuttle cars, and the challenge in both situations is to align technology upgrades with operational requirements. It is worth mentioning here that both the continuous miner and shuttle car are necessary equipment to produce coal safely from a mine.

To minimize trial and error, technical problem solving requires experiential knowledge and access to information (Sommerville and Sawyer, 1997) which, in our case study environment, means knowledge of underground coal mining conditions. The corollary is that, to specify what technology to implement also requires technological intelligence which, often times, resides with the manufacturer, vendor, or supplier rather than the operator of the equipment (Van Den Poel, 2000). Thus, it is necessary to evolve a standardized process for specifying user requirements bearing in mind that coal mining can be lethargic to technological innovations. The firm in our case study has evolved a 'standardized format' (cf. Van Wegberg, 2004) for specifying the requirements for technology 


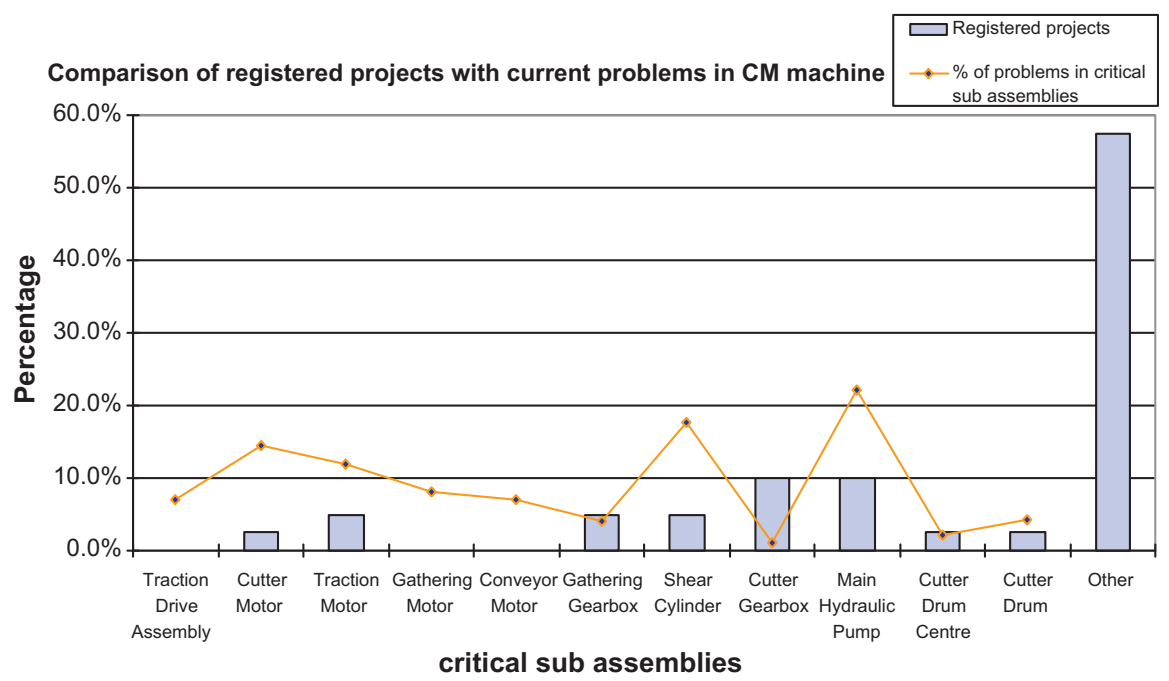

Fig. 3. A comparison of specified technology improvement requests against operational failure rates.

improvements in coal mining equipment. Requests for technology improvements are initiated by completing the appropriate forms. One of the standardization forms is an "application for registration of changes/modifications and prototype components".

In the coal mining firm under study, requests for technology upgrades, as recorded in the completed application forms, are reviewed by a standardization committee that comprises 64 members. We approached 50 committee members and asked them to rank the requirements specified in a particular set of requests on a 5-point likert scale of importance. Fourty members responded to our survey. The requests specified requirements for modifications on various sub-assemblies of a continuous miner. Each approved request was registered as a technology improvement project.

For brevity, the requirements that ranked highest were related to safety $(\mu=4.53 ; \sigma=0.64)$, followed by availability $(\mu=4.33 ; \sigma=0.84)$, and production loss impact $(\mu=4.21 ; \sigma=0.84)$. As illustrated in Fig. 3, we also compared registered technology improvement requests against the rate of occurrence of failures on the various sub-assemblies of the continuous miner. We found that current technology improvement projects matched the rate of occurrence of failures only in three subassemblies (i.e., gathering gearbox, cutter drum centre and cutter). It was pleasant to observe that some approved requests were targeting the problems on a number of sub-assemblies. What was perplexing from the data was that a significant number of registered technology improvement projects were not addressing the rate of occurrence of failures of the so-called critical sub-assemblies. On the one hand, it begs to question the requirements specified for such requests for technology improvements, while on the other hand, it supports the notion that the approved technology improvement projects may be addressing safety and ergonomic compliance more than production throughput.

\section{Case study 3-platinum mining}

Based on the findings from our earlier cases, our case study number 3 presumed that technology application in mining responds more readily to market pull rather than technology push. What this means is that, as users of technology, platinum mining firms are more likely to adopt a reactive, instead of a proactive stance on the issue of technology roadmapping. Subsequently, we developed a questionnaire directed at the management cadre of platinum mining firms, whom in our opinion, should be reasonably aware, and as such, should be in a position to provide educated responses to the questions. 


\section{Institutions performing Incremental technology innovation for the company}

\begin{tabular}{|ll|}
\hline \multicolumn{1}{|c|}{ Legend } & \\
Never & 1 \\
Seldom & 2 \\
Sometimes & 3 \\
Often & 4 \\
Always & 5 \\
\hline
\end{tabular}

\section{Institutions performing Radical technology innovation for the company}

\begin{tabular}{|lr|}
\hline \multicolumn{1}{|c|}{ Legend } & \\
Never & 1 \\
Seldom & 2 \\
Sometimes & 3 \\
Often & 4 \\
Always & 5 \\
\hline
\end{tabular}

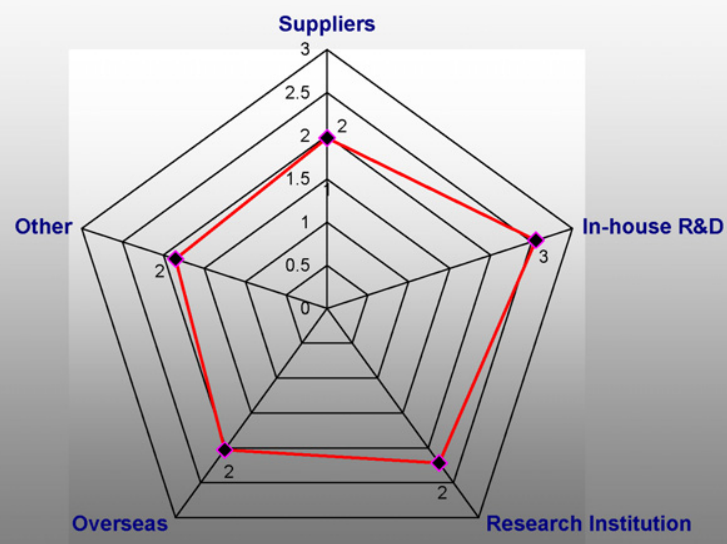

Fig. 4. Sources of technological innovation for the Case Study Platinum Mining Firm.

Following approaches to four platinum firms, only one firm was available to participate during the period of our study. The questionnaire was then sent to 52 persons of the case study firm but 41 respondents provided answers to the questions. Twenty-two respondents were engaged in specialist engineering roles, while the remaining 19 respondents represent general management and decisionmaking roles. Twelve respondents have more than 5 years experience, while 25 respondents have less than 5 years' experience in platinum mining. Only 8 respondents felt that the firm had a technology 
planning horizon greater than 5 years, whereas 28 respondents indicated a planning horizon of between 1 and 5 years. The respondent group indicated that the firm's incremental innovation cycle was about 2.5 years, and that the firm introduced radical innovation every 5 years. It is remarkable that 7 respondents said that they did not know how often the firm introduced radical innovation.

The pictures in Fig. 4 illustrate the feedback of the respondents with regard to sources of technology resources and how often these sources influence the technology direction of the firm. The
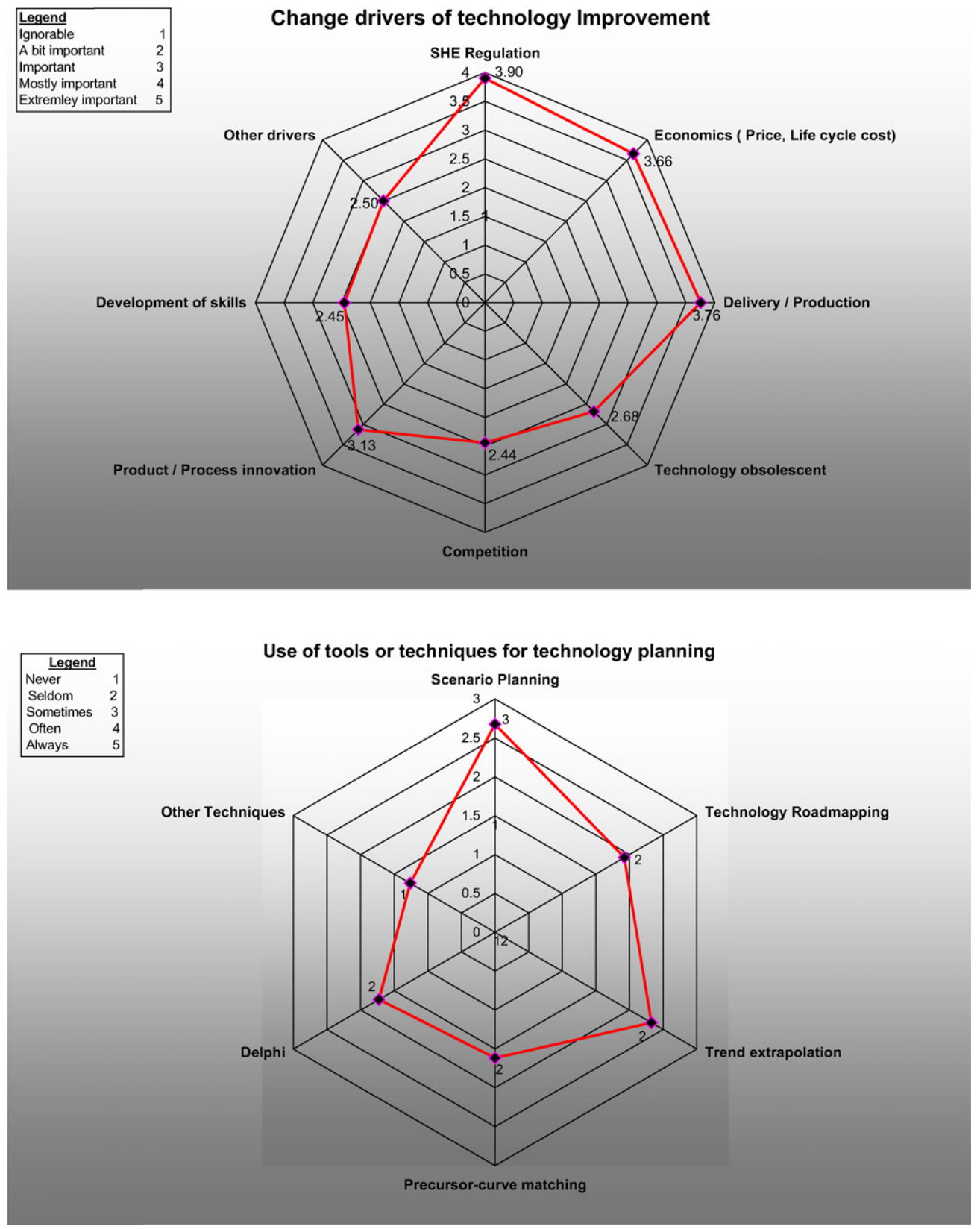

Fig. 5. Drivers and techniques for technology planning for the Case Study Platinum Mining Firm.

Please cite this article in press as: Amadi-Echendu, J., et al., Case studies of technology roadmapping in mining. J. Eng. Technol. Manage. (2011), doi:10.1016/j.jengtecman.2010.12.002 
respondents believe that suppliers, in-house research resources, and to a lesser extent, research institutions, are more likely to influence the technology direction of the platinum mining firm of our case study.

The pictures in Fig. 5 illustrate the feedback of the respondents with regard to drivers for technology improvements and the techniques used for technology planning by the mining firm. Legislation, production targets, and economics ranked as the three to drivers for technology improvements. Scenario planning and trend extrapolation were indicated as the techniques more likely to be applied for technology planning.

\section{Discussion}

Although technology roadmapping, as propounded in literature, provides a means for the development, acquisition and implementation of advanced technologies and also linking them to the business strategy, we have found, based on the non-probabilistic samples of respondents to our surveys, that scenario planning and trend analysis has been the preferred approach for mining firms. Our case studies also reiterate that safety and environment considerations create the highest impetus for technological innovations in coal mining.

During the period of the study, there was a serious global financial crisis that, in turn, had a significant influence on the mining industry. Apparently, the platinum mining firm that participated in our study was also undergoing major restructuring, and we suspect that this may have had some impact on the attention of our respondents since only 12 had more than 5 years experience. Nevertheless, extrapolating from the data, it is remarkable that legislation was most likely to induce technological change, and that the firm was more likely to use suppliers' and in-house resources to facilitate the response to the corresponding regulatory requirements. This view is not out of place because as a producer of a commodity, the firm is strongly market-driven, and may only see technology as a means to an end so that suppliers' resources may only be acquired as necessary to resolve real, rather than perceived, technological problems. Whereas the respondents felt that legislation should be the top driver for the firm to introduce technology change, however, an impression is that production targets provide the dominant impetus. This is supported by the important ranking of product/process innovation as needs driven by market demands. The suggestion here is that technology improvement would be promptly initiated and supported if it was likely to increase production while concurrently facilitating compliance to safety, health and environmental regulations.

Overall, we are left with the impression that technology planning and forecasting in mining is very much at infancy, and that the processes for technology management, at least for the mining firms that participated in our case studies, are driven by operational concerns, that is, the market-pull view rather than the technology-push view. This leads us to suggest that the technology roadmapping technique may be more suited to the technology-push view dominant with manufacturers, vendors or suppliers, instead of the market-pull view prevalent within operators of asset-intensive businesses.

Our case studies did not investigate latent issues such as the stock of knowledge of prevailing technologies, and absorptive capacity for new technologies within the firms.

\section{References}

Adner, R., Levinthal, D., 2001. Demand heterogeneity and technology evolution: implications for product and process innovation. Management Science 47 (5), 611-628.

Albright, E.R., Kappel, A.T., 2003. Roadmapping in the corporation. Research Technology Management 46, 31-39.

Amadi-Echendu, J.E., Lephauphau, O.B., Maswanganyi, M., 2008. Technology roadmapping in coal mining-a case study. In: 18th IAMOT 2009 Proceedings, Orlando, USA0-9815817-2-2.

Burgelman, R.A., Christensen, C.M., Wheelwright, S.C., 2004. Strategic Management of Technology and Innovation, 4th ed., vol. 211. pp. 975-976.

Campbell, J.D., Reyes-Picknell, J.V., 2006. UPTIME; Strategies for Excellence in Maintenance Management, 2nd ed., vol. 251. pp. 227-228.

Dyk, S.M., 2008. National assembly: questions for written reply. Department of Public Enterprises. www.dpe.gov.za (accessed 22.07.2008).

Edmondson, A.C., Winslow, A.B., Bohmer, M.J., Pisano, G.P., 2003. Effects of tacit and codified knowledge on performance improvement following technology adoption. Decision Science 34 (2), 197-223. 
Galvin, R., 2004. Roadmapping-a practitioner update. Technological Forecasting \& Social Change 101-103.

Garcia, M.L., Bray, O.H., 1997. Fundamental of TRM. Sandia National Laboratories, www.sandia.gov/ (accessed 12.06.2008).

Garg, S., Garg, S.B.L., 2005. Technology innovation as an evolutionary process. Global Journal of Flexible Systems Management 6 (1), 41-50.

Gindy, N.Z., Cerit, B., Hodgson, A., 2006. Technology roadmapping for the next generation manufacturing enterprise. Journal of Manufacturing Management 17 (4), 404-416.

Hung, J., Gerhart, D., Pix, A., Hackwood, J., 2001. Mine management system development in underground mines. Journal of South African Institute of Mining and Metallurgy 179-184.

Jain, H., Vitharana, P., Zahedi, F.M., 2003. An assessment model for requirements identification in component-based software development. Advances in Information Systems 34 (4), 48-63.

Kappel, T.A., 2001. Perspectives on roadmaps: how organizations talk about the future. Journal of Product Innovation Management 18, 39-50.

Kostoff, R.N., Boylan, R., Simons, G.R., 2004. Disruptive technology roadmaps. Technological Forecasting \& Social Change 71, $141-159$.

Lee, S., Kang, P., 2008. Applying technology roadmaps in project selection and planning. International Journal of Quality \& Reliability Management 39-51.

Limpitlaw, D., 2004. Key challenges facing the mining and minerals sector in SA. Sustainable Development Practices on Mine Sites 1-11.

Mandate Framework Document for the South African Coal Roadmap, 1998. www.fossilfuel.co.za.

McCathy, C.R., 2003. Linking technological change to business needs. Research Technology Management 46 (2), 47-52.

Peterson, D.J., Latourrette, T., Bartis, J.T., 2001. New Forces at Work in Mining: Industry Views of Critical Technologies. RAND Science and Technology Policy Institution, ISBN: 0-8330-2967-3.

Phaal, R., Farrukh, J.P., Probert, D.R., 2005. Developing a TRM system: a unifying discipline for technology management. Technology Management 99-111.

Phaal, R., Farrukh, C.J.P., Probert, D.R., 2004. Technology roadmapping-a planning framework for evolution and revolution. Technological Forecasting \& Social Change 71, 5-26.

Probert, D.R., Farrukh, C.J.P., Phaal, R., 2003. Technology roadmapping-developing a practical approach for linking resources to strategic goals. Proceedings of the Institution of Mechanical Engineers, Part B: Journal of Engineering Manufacture 217 (9), 1183-1195.

Saritas, O., Oner, M.A., 2004. Systemic analysis of UK foresight results - joint application of integrated management model and roadmapping. Technological Forecasting and Social Change 71 (1), 27-65.

Sommerville, I., Sawyer, P., 1997. Viewpoints: principles, problems and a practical approach to requirements engineering. Annals of Engineering Software 3, 101-130.

Van Den Poel, I., 2000. On the role of outsiders in technical development. Technology Analysis \& Strategic Management 12 (3), 383-397.

Van Wegberg, M., 2004. Standardisation process of systems technologies: creating a balance between competition and cooperation. Technology Analysis \& Strategic Management 16 (4), 457-478.

Von Hippel, E., 1994. Sticky information and the locus of problem solving: implications for innovation. Management Science 40 (4), 429-439.

Vojak, B.A., Chambers, F.A., 2004. Roadmapping disruptive technical threats and opportunities in complex, technology-based subsystems: the SAILS methodology. Technological Forecasting \& Social Change 71, 121-139.

Warhurst, A., Bridge, G., 1996. Improving environmental performance through innovation: recent trends in the mining industry. Minerals Engineering 9, 907-921.

Willis, R.P.H., Dixon, J.R., Cox, J.A., Pooley, A.D., 2004. A framework for introduction of mechanized mining. International Platinum Conference. The South African Institute of Mining and Metallurgy 117-124. 